\title{
Predicting resting energy expenditure in underweight, normal weight, overweight, and obese adult hospital patients
}

\author{
Hinke M. Kruizenga ${ }^{{ }^{*}}$, Geesje H. Hofsteenge ${ }^{1}$ and Peter J.M. Weijs ${ }^{1,2}$
}

\begin{abstract}
Background: When indirect calorimetry is not available, predictive equations are used to estimate resing energy expenditure (REE). There is no consensus about which equation to use in hospitalized patients. The objective of this study is to examine the validity of REE predictive equations for underweight, normal weight, overweight, and obese inpatients and outpatients by comparison with indirect calorimetry.

Methods: Equations were included when based on weight, height, age, and/or gender. REE was measured with indirect calorimetry. A prediction between 90 and 110\% of the measured REE was considered accurate. The bias and root-mean-square error (RMSE) were used to evaluate how well the equations fitted the REE measurement. Subgroup analysis was performed for BMI. A new equation was developed based on regression analysis and tested.

Results: 513 general hospital patients were included, (253 F, 260 M), 237 inpatients and 276 outpatients. Fifteen predictive equations were used. The most used fixed factors $(25 \mathrm{kcal} / \mathrm{kg} /$ day, $30 \mathrm{kcal} / \mathrm{kg} /$ day and $2000 \mathrm{kcal}$ for female and $2500 \mathrm{kcal}$ for male) were added. The percentage of accurate predicted REE was low in all equations, ranging from 8 to $49 \%$. Overall the new equation performed equal to the best performing Korth equation and slightly better than the well-known WHO equation based on weight and height (49\% vs 45\% accurate). Categorized by BMI subgroups, the new equation, Korth and the WHO equation based on weight and height performed best in all categories except from the obese subgroup. The original Harris and Benedict (HB) equation was best for obese patients.

Conclusions: REE predictive equations are only accurate in about half the patients. The WHO equation is advised up to BMI 30, and HB equation is advised for obese (over BMI 30). Measuring REE with indirect calorimetry is preferred, and should be used when available and feasible in order to optimize nutritional support in hospital inpatients and outpatients with different degrees of malnutrition.
\end{abstract}

Keywords: Resting energy expenditure, Equation, BMI, Prediction, Validity, Underweight, Normal weight, Overweight, Obese, Indirect calorimetry

\footnotetext{
* Correspondence: h.kruizenga@vumc.nl

${ }^{1}$ Department of Nutrition and Dietetics, Internal Medicine, VU University

Medical Center, P.O. Box 7057, Amsterdam 1007 MB, The Netherlands

Full list of author information is available at the end of the article
} 


\section{Background}

In clinical practice, an adequate measurement of resting energy expenditure (REE) for adult patients is important for optimal nutritional therapy in order to prevent under- and over nutrition [1]. REE in adult patients can be measured by indirect calorimetry, based on oxygen consumption and carbon dioxide production [2]. Indirect calorimetry is considered as the most accurate method [3] for determining the REE in adult patients [4, 5]; however, this measurement is time-consuming and not available in most clinical settings. As an alternative, REE is usually calculated with various REE predictive equations, based on healthy subjects $[1,6]$.

Only few studies have validated REE predictive equations in hospitalized patients [7-9]. The number of validated predictive equations is small $[7,8]$ and studies have small sample sizes [7, 9]. Therefore, there is no consensus about which equation to use in hospitalized patients. According to Boullata et al. [8], the Harris \& Benedict (1918) (HB1918) [10] equation is the best equation to predict REE, when using an illness factor of 1.1. It appeared $62 \%$ of the patients were predicted accurately using this equation. Anderegg et al. [7] suggests HB1918 with adjusted bodyweight and a stress factor, which led to $50 \%$ accurately predicted patients. Weijs et al. [9] suggest the WHO and adjusted Harris \& Benedict (HB1984) [11] equations, predicting about $50 \%$ of the patients accurately. More recently, Jesus et al. [12] showed that the original Harris \& Benedict equation (HB1918) performed reasonably, but no equation was adequate for extreme BMI groups $(<16$ and $>40)$.

Therefore, it is unclear which REE predictive equation performs most uniform across BMI subgroups for hospital patients. The aim of this study is to examine the validity of REE predictive equations for underweight, normal weight, overweight, and obese patients by comparison with indirect calorimetry.

\section{Methods}

\section{Patients}

Between March 2005 and December 2015, data were collected at the VU University Medical Center Amsterdam. Patients who had an indication for nutritional assessment by the dietitian were included in this study. All measurements were performed according to a standardized operating procedure (SOP), and personal was trained in a standardized manner. Patients were measured as part of patient care. As malnutrition is the main reason for measurement, withholding food for longer than absolutely necessary is questionable and maybe unethical. All patients were restricted from food for at least $2 \mathrm{~h}$ before the measurement. None of the patients were restricted from food for $8 \mathrm{~h}$, as the guideline [13] indicates.

Only adult patients with complete data (height, weight, age, and gender) were included. When repeated REE measurements were available, only the first measurement was included. Exclusion criteria were patients at ICU, pregnant women, and REE measurements shorter than $15 \mathrm{~min}$. All procedures were in accordance with ethical standards of the institution.

\section{Indirect calorimetry and anthropometric measurements} Indirect calorimetry measurements were performed by using a metabolic monitor (Deltatrac 2 MBM-200, Datex-Ohmeda, Helsinki, Finland; Vmax Encore n29, Viasys Healthcare, Houten, The Netherlands). Both devices were calibrated every day before use and Vmax also every $5 \mathrm{~min}$ during measurement. The Deltatrac was calibrated with one reference gas mixture $\left(95 \% \mathrm{O}_{2}, 5 \% \mathrm{CO}_{2}\right)$, whereas Vmax was calibrated with two standard gases $\left(26 \% \mathrm{O}_{2}, 0 \% \mathrm{CO}_{2}\right.$, and $16 \%$ $\mathrm{O}_{2}, 4 \% \mathrm{CO}_{2}$ ). Patients were measured in supine position. Calibration and measurements were performed by a trained dietitian. Oxygen analyser sensitivity was checked yearly by supplier.

Body weight was measured using a calibrated electronic stand-up scale (Seca Alpha, Hamburg, Germany). In case of severe oedema or when weighing was not possible, even weighing in bed, self-reported weight was used. Height of the patient was measured or selfreported. BMI was calculated as weight $(\mathrm{kg})$ divided by the square of height $\left(\mathrm{m}^{2}\right)$.

\section{REE predictive equations}

Predictive equations were obtained by a systematic search using PubMed. Mesh-derived keys 'energy metabolism', 'basal metabolism' and 'indirect calorimetry' and additional terms ('predict",' 'estimat", 'equation"' and 'formula"') were applied in every possible combination. Applied limitations were 'English language', 'humans' and the age of 18 years and older. Additional publications were checked based on reference lists. Equations were included when based on body weight, height, age, and/or gender.

The Weijs equation for overweight patients [14] was tested in patients with $\mathrm{BMI}>25$. For the BMI $<25$ subgroup, a new REE predictive equation was developed in this subpopulation with $\mathrm{BMI}<25$ using regression analysis with measured REE (kcal/ day) as dependent and body weight $(\mathrm{kg})$, height 
$(\mathrm{m})$, age $(\mathrm{y})$, and $\operatorname{sex}(\mathrm{F}=0, \mathrm{M}=1)$ as independent variables.

\section{Statistical analysis}

An independent samples $T$-test was used for differences in weight, BMI, age, and REE between inpatients and outpatients, as well as between males and females. BMI subgroups were analysed: underweight $\left(\mathrm{BMI}<18.5 \mathrm{~kg} / \mathrm{m}^{2}\right)$, normal weight (BMI $\geq 18.5-<$ $\left.25 \mathrm{~kg} / \mathrm{m}^{2}\right)$, overweight (BMI $\left.\geq 25-<30 \mathrm{~kg} / \mathrm{m}^{2}\right)$, and obese patients $\left(B M I \geq 30 \mathrm{~kg} / \mathrm{m}^{2}\right)$. The difference between the REE predictive equation and REE measured was calculated as percentage. A prediction between 90 and $110 \%$ of the REE measured was considered as accurate prediction. A prediction below $90 \%$ was considered as under prediction and a prediction over $110 \%$ was considered as over prediction. The bias indicates the mean percentage error between REE predictive equation and REE measured. The root-meansquare-error (RMSE), expressed in $\mathrm{kcal} /$ day, was used to measure how well the equations fitted the REE measurement.

To check whether in underweight and obese patients adjustment of weight in the REE predictive equation resulted in a better performance of the equation, body weight adjustment was applied (BMI < 18.5: weight adjusted to $\mathrm{BMI}=18.5$ ); $\mathrm{BMI}>30$ : weight adjusted to $\mathrm{BMI}=30$ ). The criterion for improvement of performance was percentage accurate predictions. Statistical significance was reached when $p<0.05$. Data was analysed with IBM SPSS Statistics 20.

\section{Results}

\section{Patients}

Table 1 shows characteristics of study populations. REE measurements of 593 patients were available. Eighty had incomplete data. In total, 513 general hospital patients were included, (253 F, $260 \mathrm{M})$, 237 inpatients and 276 outpatients. These patients were often complex patients with multimobidity and were categorised as oncology (29\%), gastroenterology (19\%, Diabetes/overweight (14\%), Nephrology (10\%), Lung diseases (7\%), Neurology (5\%), diagnostics in unintentional weight loss $(5 \%)$ and a rest group (8\%) of cardiology, anorexia nervosa, auto immune disease, spinal cord injury and RA patients.

\section{REE predictive equations}

In total, 15 predictive equations were used. The most used fixed factors $(25 \mathrm{kcal} / \mathrm{kg} /$ day, $30 \mathrm{kcal} / \mathrm{kg} /$ day and $2000 \mathrm{kcal}$ for female and $2500 \mathrm{kcal}$ for male) were added. These fixed factors calculate total energy expenditure and in order to provide REE, they were divided by a physical activity and/or stress factor of 1.3. Appendix 1 shows the descriptives of the included REE predictive equations.

\section{Accuracy of predictive equations}

Based on REE data of patients with $\mathrm{BMI}<25$ a new equation was developed in the current population: $\mathrm{BMI}<25$ : $\operatorname{REE}(\mathrm{kcal} /$ day $)=11.355 \times$ weight $(\mathrm{kg})+$ $7.224 \times$ height $(\mathrm{cm})-4.649 \times$ age $(y)+135.265 \times$ sex $(\mathrm{F}=0 ; \mathrm{M}=1)-137.475$; for $\mathrm{BMI} \geq 25$ an equation had been developed on healthy overweight and/or obese subjects by Weijs and Vansant [14]: BMI $\geq 25$ : REE $(\mathrm{kcal} /$ day $)=14.038 \times$ weight $(\mathrm{kg})+4.498 \times$ height $(\mathrm{cm})-0.977 \times$ age $(\mathrm{y})+137.566 \times \operatorname{sex}(\mathrm{F}=0 ; \mathrm{M}=1)-$ 221.631.

Table 2 shows statistics of the REE predictive equations for all patients. The percentage of accurate predicted REE was low in all equations, ranging from 8 to $49 \%$. Overall the new equation performed equal to the best performing Korth equation and slightly better than the well-known WHO equation based on weight and height (49\% vs $45 \%$ accurate).

Table 3 shows statistics for the best predictive equations categorized by BMI subgroups. The new equation, Korth and the WHO equation based on weight and height performed best in all categories except from the obese subgroup. HB1918 was best for obese patients.

Figure 1 shows the percentage of accurately predicted underweight and obese patients with actual as well as adjusted weight using the WHO equation with weight and height [15] and HB1918 [10]. Adjusting the weight in the equation in underweight and obese patient did not improve the percentage of patients with an accurate predicted REE.

\section{Discussion}

This study shows that for hospital inpatients and outpatients the generally applied WHO [15] and the original Harris \& Benedict equation (HB1918) [10] can only predict resting energy expenditure accurately in one of two to three patients. The generally used fixed $25 \mathrm{kcal} / \mathrm{kg}$ body weight was only accurate in $28 \%$ of the patients. The Korth equation also performed well, but not significantly better than the well implemented WHO and H\&B equations. The newly developed equation performed equal to the best performing equations but showed no additional value. Generally applied weight adjustments all failed to improve accuracy. Hospital inpatients and outpatients may still benefit from using indirect calorimetry for assessment of energy needs. 
Table 1 Patient characteristics for the total group and per BMI group

\begin{tabular}{|c|c|c|c|c|c|c|c|c|c|c|}
\hline & Total group & & $\mathrm{BMI}<18,5$ & & BMI $18,5-25$ & & BMI 25-30 & & $\mathrm{BMI}>30$ & \\
\hline \multirow[t]{2}{*}{ N (\%) } & 513 & & $141(27 \%)$ & & 209 (41\%) & & 77 (15\%) & & $86(17 \%)$ & \\
\hline & Mean & SD & Mean & SD & Mean & SD & Mean & SD & Mean & SD \\
\hline Age (y) & 53.0 & 15.6 & 51.3 & 17.0 & 54.1 & 15.2 & 55.3 & 15.2 & 50.9 & 14.2 \\
\hline$\%$ Male & $51 \%$ & & $44 \%$ & & $58 \%$ & & $53 \%$ & & $41 \%$ & \\
\hline Weight (kg) & 70.1 & 22.9 & 49.4 & 7.3 & 64.2 & 8.7 & 83.2 & 11.0 & 106.7 & 21.3 \\
\hline Height (m) & 1.73 & 0.10 & 1.72 & 0.10 & 1.74 & 0.09 & 1.74 & 0.10 & 1.71 & 0.12 \\
\hline BMI $\left(\mathrm{kg} / \mathrm{m}^{2}\right)$ & 23.4 & 7.2 & 16.6 & 1.5 & 21.3 & 1.8 & 27.3 & 1.4 & 36.3 & 5.4 \\
\hline REE (kcal/day) & 1678 & 408 & 1448 & 318 & 1696 & 358 & 1730 & 352 & 1966 & 488 \\
\hline REE in kcal/kg/day (range) & $25.1(12-53)$ & 6.2 & $29.4(18-43)$ & 5.5 & $26.6(14-53)$ & 5.3 & $20.8(12-31)$ & 3.3 & $18.5(13-29)$ & 3.2 \\
\hline$\%$ inpatients & $46 \%$ & & $57 \%$ & & $55 \%$ & & $35 \%$ & & $17 \%$ & \\
\hline
\end{tabular}

Studies by Anderegg et al. [7] and Boullata et al. [8] analysed (in part) mechanically ventilated patients and are therefore more difficult to compare to current inpatient and outpatient analysis. However, in general they also showed rather inaccurate estimates using different REE estimating equations. Based on a similar analysis with a much smaller sample size, Weijs et al. [9] concluded that the WHO equation (1985) [15] based on weight and height and Harris \& Benedict (1984) [11] were the best predictive equations. The current analysis confirms that the overall accuracy of REE predictive equations is only about $50 \%$, however this study extends this analysis to BMI subgroups for which predictive accuracy may in fact be much worse.

Table 2 Statistics of REE prediction equation performance, $\mathrm{N}=513$

\begin{tabular}{|c|c|c|c|c|c|c|c|}
\hline & REE (kcal/day) & SD & Under prediction (\%) ${ }^{a}$ & Accurate prediction (\%) ${ }^{b}$ & Over prediction (\%) ${ }^{c}$ & BIAS $^{d}$ & RMSE $^{\circ}$ \\
\hline REE by calorimetrie & 1678 & 408 & & & & & \\
\hline New equation & 1698 & 313 & 19 & 49 & 32 & 4 & 286 \\
\hline Korth [18] & 1621 & 344 & 30 & 49 & 22 & -1 & 295 \\
\hline WHO-wtht [15] & 1540 & 288 & 40 & 45 & 14 & -6 & 321 \\
\hline Schofield-wtht [19] & 1513 & 282 & 46 & 42 & 12 & -7 & 333 \\
\hline Henry-wtht [20] & 1489 & 291 & 51 & 39 & 10 & -9 & 344 \\
\hline WHO-wt [15] & 1504 & 304 & 49 & 39 & 13 & -8 & 345 \\
\hline Harris\& Benedict 1918 [10] & 1490 & 324 & 51 & 38 & 11 & -9 & 350 \\
\hline Muller [21] & 1493 & 308 & 52 & 37 & 11 & -9 & 347 \\
\hline H\&B by Roza [11] & 1494 & 321 & 53 & 37 & 11 & -9 & 344 \\
\hline Schofield-wt [19] & 1483 & 293 & 53 & 36 & 12 & -9 & 355 \\
\hline Mifflin [22] & 1444 & 304 & 60 & 32 & 8 & -12 & 369 \\
\hline Henryz2005-wt [20] & 1458 & 320 & 58 & 31 & 10 & -11 & 370 \\
\hline MullerBMI [21] & 1396 & 435 & 60 & 31 & 9 & -16 & 450 \\
\hline $30 \mathrm{kcal} / \mathrm{kg}$ & 1618 & 527 & 44 & 28 & 28 & -2 & 435 \\
\hline Livingston [23] & 1405 & 284 & 66 & 27 & 7 & -14 & 399 \\
\hline $25 \mathrm{kcal} / \mathrm{kg}$ & 1348 & 440 & 68 & 23 & 9 & -19 & 502 \\
\hline $\begin{array}{l}2000 \mathrm{kcal} \text { for female and } \\
2500 \mathrm{kcal} \text { for male }\end{array}$ & 2253 & 250 & 3 & 11 & 87 & 41 & 689 \\
\hline Bernstein [24] & 1208 & 271 & 90 & 8 & 2 & -26 & 557 \\
\hline
\end{tabular}

${ }^{a}$ The percentage of subjects predicted by this predictive equation $<10 \%$ of the measured value

${ }^{b}$ The percentage of subjects predicted by this predictive equation within $10 \%$ of the measured value

c The percentage of subjects predicted by this predictive equation $>10 \%$ of the measured value

${ }^{\mathrm{d}}$ Mean percentage error between predictive equation and measured value

${ }^{\mathrm{e}}$ Root mean squared prediction error 
Table 3 REE predictive accuracy of prediction equations in BMI subgroups

\begin{tabular}{|c|c|c|c|c|c|c|c|c|c|c|c|c|c|c|c|}
\hline & \multicolumn{3}{|c|}{ Total group $(n=513)$} & \multicolumn{3}{|c|}{$\mathrm{BMI}<18.5(\mathrm{n}=141)$} & \multicolumn{3}{|c|}{ BMI 18.5-25 $(n=209)$} & \multicolumn{3}{|c|}{ BMI 25-30 $(n=77)$} & \multicolumn{3}{|c|}{$\mathrm{BMI}>30(\mathrm{n}=86)$} \\
\hline & $\begin{array}{l}\text { Under } \\
\text { predic-tion }\end{array}$ & $\begin{array}{l}\text { Accu- } \\
\text { rate }\end{array}$ & $\begin{array}{l}\text { Over } \\
\text { predic-tion }\end{array}$ & $\begin{array}{l}\text { Under } \\
\text { predic-tion }\end{array}$ & $\begin{array}{l}\text { Accu- } \\
\text { rate }\end{array}$ & $\begin{array}{l}\text { Over } \\
\text { predic-tion }\end{array}$ & $\begin{array}{l}\text { Under } \\
\text { predic-tion }\end{array}$ & $\begin{array}{l}\text { Accu- } \\
\text { rate }\end{array}$ & $\begin{array}{l}\text { Over } \\
\text { predic-tion }\end{array}$ & $\begin{array}{l}\text { Under } \\
\text { predic-tion }\end{array}$ & $\begin{array}{l}\text { Accu- } \\
\text { rate }\end{array}$ & $\begin{array}{l}\text { Over } \\
\text { predic-tion }\end{array}$ & $\begin{array}{l}\text { Under } \\
\text { predic-tion }\end{array}$ & $\begin{array}{l}\text { Accu- } \\
\text { rate }\end{array}$ & $\begin{array}{l}\text { Over } \\
\text { predic-tion }\end{array}$ \\
\hline & $\%$ & $\%$ & $\%$ & $\%$ & $\%$ & $\%$ & $\%$ & $\%$ & $\%$ & $\%$ & $\%$ & $\%$ & $\%$ & $\%$ & $\%$ \\
\hline New equation & 19 & 49 & 32 & 21 & 44 & 35 & 22 & 51 & 27 & 14 & 58 & 27 & 14 & 44 & 42 \\
\hline Korth [18] & 30 & 49 & 22 & 35 & 40 & 24 & 34 & 52 & 14 & 17 & 56 & 27 & 22 & 48 & 30 \\
\hline WHO-wtht [15] & 40 & 45 & 14 & 40 & 45 & 14 & 48 & 43 & 9 & 27 & 55 & 18 & 33 & 44 & 23 \\
\hline Schofield-wtht [19] & 46 & 42 & 12 & 43 & 44 & 13 & 54 & 40 & 7 & 36 & 48 & 16 & 40 & 40 & 21 \\
\hline Henry-wtht [20] & 51 & 39 & 10 & 50 & 37 & 13 & 60 & 35 & 4 & 40 & 45 & 14 & 38 & 45 & 16 \\
\hline WHO-wt [15] & 49 & 39 & 13 & 52 & 35 & 12 & 60 & 33 & 7 & 30 & 53 & 17 & 31 & 45 & 23 \\
\hline Harris \& Benedict 1918 [10] & 51 & 38 & 11 & 60 & 27 & 13 & 63 & 33 & 3 & 34 & 53 & 13 & 26 & 53 & 21 \\
\hline Muller [21] & 52 & 37 & 11 & 59 & 29 & 12 & 62 & 33 & 5 & 38 & 48 & 14 & 28 & 51 & 21 \\
\hline H\&B by Roza [11] & 53 & 37 & 11 & 57 & 30 & 13 & 65 & 33 & 3 & 39 & 45 & 16 & 29 & 50 & 21 \\
\hline Schofield-wt [19] & 53 & 36 & 12 & 54 & 33 & 13 & 61 & 32 & 7 & 42 & 47 & 12 & 40 & 40 & 21 \\
\hline Mifflin [22] & 58 & 33 & 8 & 60 & 28 & 12 & 66 & 30 & 4 & 45 & 45 & 9 & 48 & 40 & 13 \\
\hline Henry-wt [20] & 60 & 32 & 8 & 60 & 28 & 12 & 67 & 29 & 4 & 49 & 43 & 8 & 52 & 37 & 10 \\
\hline MullerBMI [21] & 60 & 32 & 8 & 63 & 27 & 10 & 70 & 27 & 3 & 48 & 43 & 9 & 43 & 43 & 14 \\
\hline $30 \mathrm{kcal} / \mathrm{kg}$ & 58 & 31 & 10 & 67 & 23 & 11 & 69 & 27 & 4 & 40 & 45 & 14 & 35 & 43 & 22 \\
\hline Livingston [23] & 60 & 31 & 9 & 99 & 1 & 0 & 55 & 36 & 9 & 39 & 47 & 14 & 29 & 50 & 21 \\
\hline $25 \mathrm{kcal} / \mathrm{kg}$ & 44 & 28 & 28 & 78 & 16 & 6 & 51 & 39 & 11 & 8 & 40 & 52 & 5 & 10 & 85 \\
\hline $\begin{array}{l}2000 \mathrm{kcal} \text { for female and } \\
2500 \mathrm{kcal} \text { for male }\end{array}$ & 66 & 27 & 7 & 73 & 19 & 8 & 73 & 23 & 3 & 53 & 39 & 8 & 50 & 38 & 12 \\
\hline Bernstein [24] & 68 & 23 & 9 & 91 & 9 & 0 & 86 & 12 & 2 & 40 & 49 & 10 & 14 & 47 & 40 \\
\hline
\end{tabular}

Accurate prediction: the percentage of subjects predicted by this predictive equation within $10 \%$ of the measured value

Underprediction: the percentage of subjects predicted by this predictive equation $<10 \%$ of the measured value

Overprediction: the percentage of subjects predicted by this predictive equation $>10 \%$ of the measured value 


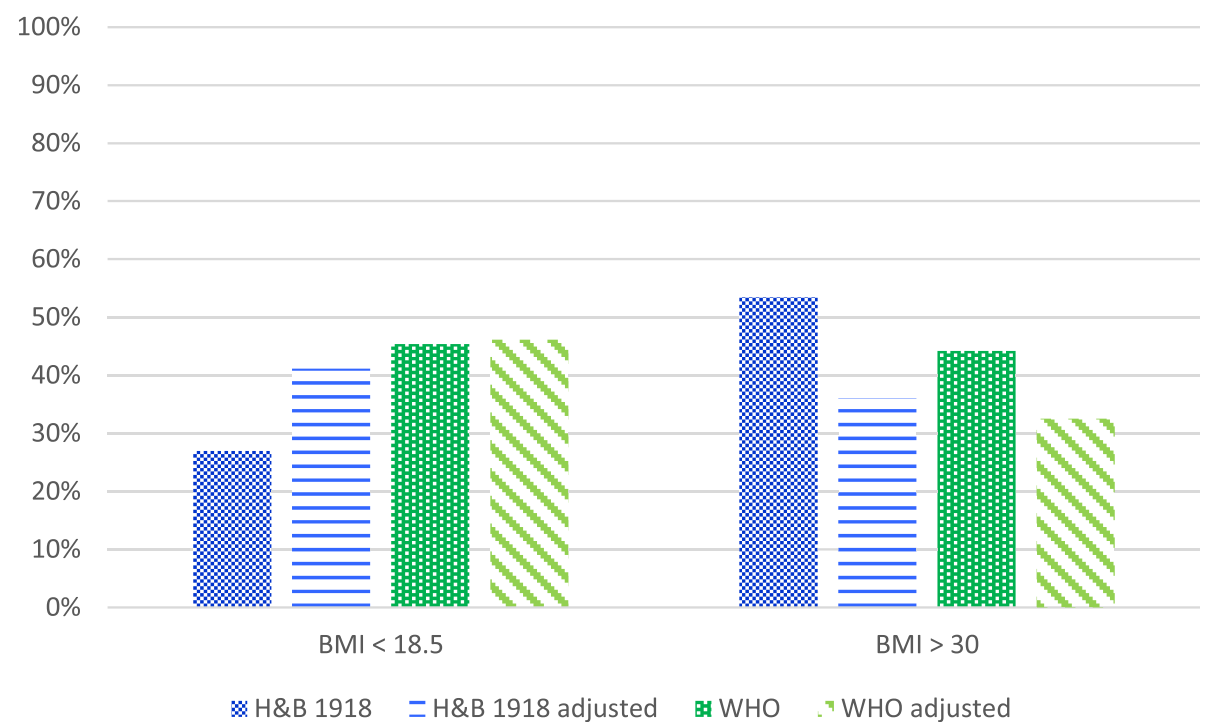

Fig. 1 The percentage of accurately predicted underweight and obese patients with actual as well as adjusted weight (BMI < 18.5: weight adjusted to $\mathrm{BMl}=18.5) ; \mathrm{BMI}>30$ : weight adjusted to $\mathrm{BMI}=30$ )

Jesus et al. [12] showed that the overall accuracy of the Harris \& Benedict equation was reasonable for the outpatient sample. The authors stress that predictive accuracy is much worse in extreme BMI subgroups with BMI under 16 and BMI over 40. The current study generally supports these conclusions, however extend these observations in two ways. First, the general accuracy is not that much higher in the normal weight patient group, in fact accuracy increases to highest level in overweight subgroup. Secondly, we agree that the subgroup of patients with BMI less than 16 has a low prediction accuracy, however we have also shown low prediction accuracy for a large cohort of malnourished hospitalized elderly with mean BMI 21 (SD 4) [16]. Therefore, the suggestion that predictive equations perform well between BMI 16 and BMI 40 is largely false for hospital patients.

According to Frankenfield et al. [17], adjusting body weight in obese patients leads to underestimation of the energy expenditure. When this is done with a fixed BMI level, the adjustment appears too large and does not result in a higher accuracy of REE prediction. However, accuracy remains low in all predictions.

This study has several strengths and limitations. The sample size of 513 patients was large enough for subgroup analysis, namely BMI subgroups. Furthermore, these data were derived from daily clinical practice and therefore the study population is representative for the inpatient and outpatient population. Another advantage is the exclusion of ICU patients that may not be entirely comparable to the general hospital population. Therefore, this study has a large generalizability to other hospitals and patients.

However, this study has some limitations as well. The measurements were performed in clinical practice and therefore patients were not measured in overnight fasted state. However, since patients were measured because of nutritional problems, the thermic effect of larger meals, if any, were not a problem in this patient sample. This could have been a problem in obese outpatients, however according to the results the estimations are most accurate in this subgroup. Only when the dietitian indicated the patient for nutritional assessment, a measurement was performed. This may have led to selection bias as only patients who were difficult to assess and/or treat were included in this study. This may largely explain the low level of accuracy in the current analysis.

This study population was too small to develop a new equation for the hospital in and outpatients. The variation of REE between patients and probably between disease groups is too large. A possible way forward, is to develop new equations in more homogenous subgroups. For this purpose a very large database would be needed on REE in hospital patients. We propose to develop an REE repository for clinical data, comparable to the Oxford database on REE in healthy subjects. This could be jointly organised within ESPEN and ASPEN.

\section{Conclusions}

In conclusion, REE predictive equations are only accurate in about half the patients. The WHO equation is advised up to BMI 30, and HB1918 equation is advised for obese (over BMI 30). Measuring REE with indirect calorimetry is preferred, and should be used when available and feasible in order to optimize nutritional support in hospital inpatients and outpatients with different degrees of malnutrition. 


\section{Appendix 1}

Table 4 Descriptives of included predictive equations

\begin{tabular}{|c|c|c|c|}
\hline $\begin{array}{l}\text { Author, year of publication and } \\
\text { referred to as }\end{array}$ & Study population and $\mathrm{n}$ & $\begin{array}{l}\text { Age (mean } \pm S D \text { or } \\
\text { range) }\end{array}$ & REE Equations (kcal/day) \\
\hline \multirow[t]{2}{*}{ Bernstein, 1983 [24] } & \multirow{2}{*}{$\begin{array}{l}\text { Obese individuals; patients who } \\
\text { enrolled the Weight Control Unit } \\
\text { of the Obesity Research Center IC } \\
\text { instrument: Beckman } \\
n: 48 \mathrm{M} / 154 \mathrm{~F}\end{array}$} & M: $39 \pm 12$ y & M: $11.02 \times \mathrm{WT}+10.23 \times \mathrm{HTCM}-5.8 \times$ AGE -1032 \\
\hline & & $F: 40 \pm 13$ y & F: $7.48 \times$ WT $-0.42 \times$ HTCM $-3.0 \times$ AGE +844 \\
\hline \multirow{13}{*}{$\begin{array}{l}\text { FAO/WHO/UNU, } 1985 \text { [15] } \\
\text { WHO-wt } \\
\text { WHO-wtht }\end{array}$} & \multirow[t]{13}{*}{ n: $575 \mathrm{M} / 734 \mathrm{~F}$} & \multirow[t]{13}{*}{ All: $30-82 y$} & M 18-30: $(15.3 \times$ WT) + 679 \\
\hline & & & F 18-30: $(14.7 \times$ WT $)+496$ \\
\hline & & & M 30-60: $(11.6 \times$ WT $)+879$ \\
\hline & & & F 30-60: $(8.7 \times$ WT $)+829$ \\
\hline & & & M 60+: $(13.5 \times$ WT $)+487$ \\
\hline & & & F 60+: $(10.5 \times$ WT $)+596$ \\
\hline & & & Equations based on weight and height \\
\hline & & & M 18-30: $(15.4 \times$ WT $)-(27 \times$ HTM $)+717$ \\
\hline & & & F 18-30: $(13.3 \times$ WT $)+(334 \times$ HTM $)+35$ \\
\hline & & & M 30-60: $(11.3 \times$ WT $)+(16 \times$ HTM $)+901$ \\
\hline & & & F 30-60: $(8.7 \times$ WT $)-(25 \times$ HTM $)+865$ \\
\hline & & & M 60+: $(8.8 \times$ WT $)+(1128 \times$ HTM $)-1071$ \\
\hline & & & F 60+: $(9.2 \times$ WT $)+(637 \times$ HTM $)-302$ \\
\hline \multirow[t]{2}{*}{ Harris \& Benedict, 1918 [10] } & \multirow[t]{2}{*}{ n: $136 \mathrm{M} / 103 \mathrm{~F}$} & M: $27 \pm 9(16-63)$ y & $\begin{array}{l}\text { M: } 66.4730+(13.7516 \times \text { WT })+(5.0033 \times \text { HTCM })- \\
(6.7550 \times \text { AGE })\end{array}$ \\
\hline & & $F: 31 \pm 14(15-74)$ y & $\begin{array}{l}\text { F: } 655.0955+(9.5634 \times \text { WT })+(1.8496 \times \text { HTCM })- \\
(4.6756 \times \text { AGE })\end{array}$ \\
\hline \multirow{2}{*}{$\begin{array}{l}\text { Harris \& Benedict, } 1984 \text { Roza } \\
\text { \& Shizgal [11] } \\
\text { H\&B by Roza }\end{array}$} & \multirow{2}{*}{$\begin{array}{l}\text { Data of Harris \& Benedict (1918) } \\
\text { and data of two further studies } \\
\text { by Benedict with data on } \\
\text { additional subjects ( } n \text { : } 168 \mathrm{M} / 169 \mathrm{~F} \text { ) }\end{array}$} & M: $30 \pm 14$ y & $\begin{array}{l}\text { M: } 88.362+(13.397 \times \text { WT })+(4.799 \times \text { HTCM })- \\
(5.677 \times \text { AGE })\end{array}$ \\
\hline & & $F: 44 \pm 22$ y & $\begin{array}{l}F: 447.593+(9.247 \times W T)+(3.098 \times H T C M)- \\
(4.330 \times \text { AGE })\end{array}$ \\
\hline \multirow[t]{2}{*}{ Korth, 2007 [18] } & \multirow{2}{*}{$\begin{array}{l}\text { Healthy euthyroid weight stable } \\
\text { subjects who were recruited by } \\
\text { local announcements } \\
n: 50 \mathrm{M} / 54 \mathrm{~F}\end{array}$} & M: $39 \pm 14(21-68)$ y & $\begin{array}{l}\text { All: }(41.5 \times \text { WT })-(19.1 \times \text { AGE })+(35.0 \times \text { HTCM })+ \\
(1107.4 \times \text { SEX })-1731.2 / 4.184\end{array}$ \\
\hline & & $F: 35 \pm 15(20-66)$ y & \\
\hline \multirow[t]{2}{*}{ Livingston, 2005 [23] } & \multirow{2}{*}{$\begin{array}{l}\text { Institute of Medicine population } \\
n: 299 \mathrm{M} / 356 \mathrm{~F}\end{array}$} & M: $36 \pm 15(18-95)$ y & M: $293 \times W T^{0.4330}-(5.92 \times A G E)$ \\
\hline & & $F: 39 \pm 13(18-77) y$ & $F: 248 \times W T^{0.4356}-(5.09 \times A G E)$ \\
\hline \multirow[t]{2}{*}{ Mifflin, 1990 [22] } & \multirow{2}{*}{$\begin{array}{l}\text { IC instrument: metabolic } \\
\text { measurement cart with a canopy } \\
\text { hood (Metabolic Measurement } \\
\text { Cart Horizons System) } \\
n: 251 \text { M (122 obese)/247 F } \\
\text { (112 obese) }\end{array}$} & M: $44 \pm 14(19-78)$ y & M: $(9.99 \times$ WT $)+(6.25 \times$ HTCM $)-(4.92 \times$ AGE $)+5$ \\
\hline & & $F: 45 \pm 14(20-76)$ y & F: $(9.99 \times$ WT $)+(6.25 \times$ HTCM $)-(4.92 \times$ AGE $)-161$ \\
\hline \multirow[t]{2}{*}{ Muller, 2004 [21] } & \multirow{5}{*}{$\begin{array}{l}\text { Data from seven different research } \\
\text { centers in Germany } \\
\text { IC instruments: Deltatrac, Beckman, } \\
\text { Mouthpiece (metabolic chamber) } \\
\text { n } \mathrm{BMI}<18.5: 58 \\
\text { n } \mathrm{BMI} \text { 18.5-25: } 444 \\
\text { n } \mathrm{BMI} \text { 25-30: } 266 \\
n \mathrm{BMI}>30: 278\end{array}$} & $\begin{array}{l}\mathrm{BMI} \leq 18.5: 32 \pm 12 \\
\mathrm{y}\end{array}$ & $\begin{array}{l}\text { All: }(0.047 \times \text { WT })+(1.009 \times \text { SEX })-(0.01452 \times \text { AGE })+ \\
3.21 / 4.184 \times 1000\end{array}$ \\
\hline & & $\begin{array}{l}\mathrm{BMI}>18.5-25: 38 \pm \\
17 \text { y }\end{array}$ & $\begin{array}{l}\mathrm{BMI} \leq 18.5:(0.07122 \times \mathrm{WT})-(0.02149 \times \mathrm{AGE})+ \\
(0.82 \times \mathrm{SEX})+0.731 / 4.184 \times 1000\end{array}$ \\
\hline Muller & & $\begin{array}{l}\mathrm{BMI}>25-30: 53 \pm \\
16 \text { y }\end{array}$ & $\begin{array}{l}\mathrm{BMI}>18.5-25:(0.02219 \times \mathrm{WT})+(0.02118 \times \mathrm{HTCM})+ \\
(0.884 \times \text { SEX })-(0.01191 \times \text { AGE })+1.233 / 4.184 \times 1000\end{array}$ \\
\hline \multirow[t]{2}{*}{ MullerBMl } & & $\mathrm{BMI} \geq 30: 47 \pm 13$ y & $\begin{array}{l}\mathrm{BMI}>25-30:(0.04507 \times \mathrm{WT})+(1.006 \times \mathrm{SEX})- \\
(0.01553 \times \mathrm{AGE})+3.407 / 4.184 \times 1000\end{array}$ \\
\hline & & & $\begin{array}{l}\mathrm{BMI} \geq 30:(0.05 \times \mathrm{WT})+(1.103 \times \mathrm{SEX})- \\
(0.01586 \times \mathrm{AGE})+2.924 / 4.184 \times 1000\end{array}$ \\
\hline
\end{tabular}


Table 4 Descriptives of included predictive equations (Continued)

\begin{tabular}{lll}
\hline Henry, 2005 [20] & Worldwide population (excluded & M 18-30: 22 y \\
Italian subjects) from several papers & F 18-30: 22 y \\
M 18-30 y: 2821/2816 & M 30-60: 40 y \\
F 18-30 y: 1664/1655 & M 30-60 y: 1010/1006 & F 30-60: 41 y \\
F 30-60 y: 1023/1023 & M 60+ y: 534/533 & M 60+: 70 y \\
F 60+ y: 334/324 & F 60+: 69 y
\end{tabular}

Henry-wtht

Schofield, 1985 [19]

Schofield-wt
Collection of different authors and

papers

M 18-30 y: 2879

M 30-60 y: 646

M 60+ y: 50

F 18-30 y: 829

F 30-60 y: 372

F 60+ y: 38
M 18-30: 22 y

F 18-30: 22 y

M 30-60: 40 y

F 30-60: 40 y

M 60+: 72 y

F 60+: 66 y
M 18-30 y: $(16 \times W T)+545$
F 18-30 y: $(13.1 \times W T)+558$
M 30-60 y: $(14.2 \times W T)+593$
F 30-60 y: $(9.74 \times W T)+694$
M 60+ y: $(13.5 \times W T)+514$
F 60+ y: $(10.1 \times W T)+569$

Equations based on weight and height

M 18-30 y: $(14.4 \times$ WT $)+(313 \times$ HTM $)+113$

F 18-30 y: $(10.4 \times$ WT $)+(615 \times$ HTM $)-282$

M 30-60 y: $(11.4 \times$ WT $)+(541 \times$ HTM $)-137$

F 30-60 y: $(8.18 \times$ WT $)+(502 \times$ HTM $)-11.6$

M 60+ y: $(11.4 \times$ WT $)+(541 \times$ HTM $)-256$

F 60+ y: $(8.52 \times$ WT $)+(421 \times$ HTM $)+10.7$

M 18-30 y: $(0.063 \times$ WT $)+2.896 / 4.184 \times 1000$

F 18-30 y: $(0.062 \times W T)+2.036 / 4.184 \times 1000$

M 30-60 y: $(0.048 \times$ WT $)+3.653 / 4.184 \times 1000$

F 30-60 y: $(0.034 \times W T)+3.538 / 4.184 \times 1000$

M 60+ y: $(0.049 \times W T)+2.459 / 4.184 \times 1000$

F 60+ y: $(0.038 \times W T)+2.755 / 4.184 \times 1000$

Equations based on weight and height

M 18-30 y: $(0.063 \times$ WT $)-(0.042 \times$ HTM $)+$ $2.953 / 4.184 \times 1000$

F 18-30 y: $(0.057 \times$ WT $)+(1.184 \times$ HTM $)+$ $0.411 / 4.184 \times 1000$

M 30-60 y: $(0.048 \times$ WT $)-(0.011 \times$ HTM $)+$ $3.67 / 4.184 \times 1000$

F 30-60 y: $(0.034 \times$ WT $)+(0.006 \times$ HTM $)+$ $3.53 / 4.184 \times 1000$

M 60+ y: $(0.038 \times$ WT $)+(4.068 \times$ HTM $)-$ $3.491 / 4.184 \times 1000$

F $60+y:(0.033 \times$ WT $)+(1.917 \times$ HTM $)+$ $0.074 / 4.184 \times 1000$

$M$ male, $F$ female, $y$ years, $W T$ weight in kilogram, HTM height in meters, HTCM height in centimetres; SEX (male $=1$, female $=0$ ) sex, REE resting energy expenditure; $k c a l / d$ kilocalories a day, IC indirect calorimetry

\section{Abbreviations}

BMI: Body Mass Index; H\&B: Harris \& Benedict; ICU: Intensive Care Unit; REE: Resting energy expenditure; WHO: World Health Organisation

\section{Acknowledgments}

This study was supported by the VU University Medical Center, Amsterdam, the Netherlands. We thank the dietetic team of the VU University Medical Center Amsterdam for indirect calorimetry measurements and students for their support in the project.

\section{Funding}

Not applicable.
Authors' contributions

HK, GH and PW designed the study, performed literature search, data analysis, and writing of the manuscript, and confirmed final draft of the manuscript.

\section{Competing interests}

The authors declare that they have no competing interests.

\section{Consent for publication}

Not applicable.

\section{Ethics approval and consent to participate}

All measurements took place in daily clinical practice. Data were anonymised. All procedures were in accordance with ethical standards of the institution. 


\section{Author details}

'Department of Nutrition and Dietetics, Internal Medicine, VU University Medical Center, P.O. Box 7057, Amsterdam 1007 MB, The Netherlands. ${ }^{2}$ Department of Nutrition and Dietetics, School of Sports and Nutrition, Amsterdam University of Applied Sciences, Amsterdam, The Netherlands.

Received: 21 September 2016 Accepted: 15 November 2016

Published online: 24 November 2016

\section{References}

1. Fraipont V, Preiser J-C. Energy estimation and measurement in critically ill patients. JPEN J Parenter Enteral Nutr. 2013;37(6):705-13.

2. Acheson KJ. Indirect calorimetry: a case for improved standard operating procedures. Eur J Clin Nutr. 2014;68(1):1.

3. Phang PT, Rich T, Ronco J. A validation and comparison study of two metabolic monitors. JPEN J Parenter Enteral Nutr. 1990;14(3):259-61.

4. Haugen HA, Chan L-N, Li F. Indirect calorimetry: a practical guide for clinicians. Nutr Clin Pract. 2007;22(4):377-88.

5. Flancbaum L, Choban PS, Sambucco S, Verducci J, Burge JC. Comparison of indirect calorimetry, the Fick method, and prediction equations in estimating the energy requirements of critically ill patients. Am J Clin Nutr. 1999:69(3):461-6.

6. Sundström M, Tjäder I, Rooyackers $\mathrm{O}$, Wernerman J. Indirect calorimetry in mechanically ventilated patients. A systematic comparison of three instruments. Clin Nutr. 2013;32(1):118-21.

7. Anderegg BA, Worrall C, Barbour E, Simpson KN, Delegge M. Comparison of resting energy expenditure prediction methods with measured resting energy expenditure in obese, hospitalized adults. JPEN J Parenter Enteral Nutr. 2009;33(2):168-75.

8. Boullata J, Williams J, Cottrell F, Hudson L, Compher C. Accurate determination of energy needs in hospitalized patients. J Am Diet Assoc. 2007;107(3):393-401

9. Weijs PJM, Kruizenga HM, van Dijk AE, van der Meij BS, Langius JAE, Knol $D L$, et al. Validation of predictive equations for resting energy expenditure in adult outpatients and inpatients. Clin Nutr. 2008;27(1):150-7.

10. Harris JA, Benedict FG. A Biometric Study of Human Basal Metabolism. Proc Natl Acad Sci U S A. 1918:4(12):370-3.

11. Roza AM, Shizgal HM. The Harris Benedict equation reevaluated: resting energy requirements and the body cell mass. Am J Clin Nutr. 1984; 40(1):168-82.

12. Jésus $P$, Achamrah N, Grigioni $S$, Charles J, Rimbert A, Folope $V$, et al. Validity of predictive equations for resting energy expenditure according to the body mass index in a population of 1726 patients followed in a Nutrition Unit. Clin Nutr. 2015:34(3):529-35.

13. Compher C, Frankenfield D, Keim N, Roth-Yousey L. Best practice methods to apply to measurement of resting metabolic rate in adults: a systematic review. J Am Diet Assoc. 2006;106(6):881-903.

14. Weijs PJM, Vansant GAAM. Validity of predictive equations for resting energy expenditure in Belgian normal weight to morbid obese women. Clin Nutr. 2010:29(3):347-51.

15. Food and Agricutural Organization. Human energy requirements: Report of a Joint FAO/WHO/UNU Expert Consultation. FAO Food Nutr Tech Rep Ser [Internet]. 2001;0:96. Available from: ftp://ftp.fao.org/docrep/fao/007/y5686e/ y5686e00.pdf.

16. Neelemaat F, van Bokhorst-de van der Schueren MAE, Thijs A, Seidell JC, Weijs PJM. Resting energy expenditure in malnourished older patients at hospital admission and three months after discharge: predictive equations versus measurements. Clin Nutr. 2012;31(6):958-66.

17. Frankenfield DC, Rowe WA, Smith JS, Cooney RN Validation of several established equations for resting metabolic rate in obese and nonobese people. J Am Diet Assoc. 2003;103(9):1152-9.

18. Korth O, Bosy-Westphal A, Zschoche P, Glüer CC, Heller M, Müller MJ. Influence of methods used in body composition analysis on the prediction of resting energy expenditure. Eur J Clin Nutr. 2007:61(5):582-9.

19. Schofield WN. Predicting basal metabolic rate, new standards and review of previous work. Hum Nutr Clin Nutr. 1985:39 Suppl 1:5-41.

20. Henry CJK. Basal metabolic rate studies in humans: measurement and development of new equations. Public Health Nutr. 2005;8(7A):1133-52.

21. Müller MJ, Bosy-Westphal A, Klaus S, Kreymann G, Lührmann PM, Neuhäuser-Berthold $M$, et al. World Health Organization equations have shortcomings for predicting resting energy expenditure in persons from a modern, affluent population: generation of a new reference standard from a retrospective analysis of a German database of resting energy expe. Am J Clin Nutr. 2004;80(5):1379-90

22. Mifflin MD, St Jeor ST, Hill LA, Scott BJ, Daugherty SA, Koh YO. A new predictive equation for resting energy expenditure in healthy individuals. Am J Clin Nutr. 1990:51(2):241-7.

23. Livingston $\mathrm{EH}$, Kohlstadt I. Simplified resting metabolic rate-predicting formulas for normal-sized and obese individuals. Obes Res. 2005;13(7): 1255-62.

24. Bernstein RS, Thornton JC, Yang MU, Wang J, Redmond AM, Pierson RN, et al. Prediction of the resting metabolic rate in obese patients. Am J Clin Nutr. 1983;37(4):595-602.

\section{Submit your next manuscript to BioMed Central and we will help you at every step:}

- We accept pre-submission inquiries

- Our selector tool helps you to find the most relevant journal

- We provide round the clock customer support

- Convenient online submission

- Thorough peer review

- Inclusion in PubMed and all major indexing services

- Maximum visibility for your research

Submit your manuscript at www.biomedcentral.com/submit
Biomed Central 